\title{
Divulgação científica em torno do palavrão: Uma análise da recontextualização do discurso sobre ciência na mídia impressa
}

\section{Scientific dissemination about bad words: Analysis of the recontextualization of scientific discourse in the print media}

\author{
Carlos Alexandre Molina Noccioli ${ }^{1}$ \\ Cristiane Cataldi dos Santos Paes ${ }^{2}$
}

\begin{abstract}
RESUMO: Neste trabalho, ancorado no arcabouço teórico-metodológico da Análise do Discurso da Divulgação Científica e da Teoria das Representações Sociais, busca-se analisar o tratamento linguístico-discursivo de informações, dado pela mídia impressa brasileira, acerca de um tópico temático tradicionalmente visto como tabu. Para tanto, elegemos uma reportagem publicada na revista Superinteressante, que trata sobre conhecimentos científicos em torno do palavrão. Posteriormente, descrevemos e analisamos estratégias linguístico-discursivas utilizadas pelos jornalistas no processo de recontextualização das informações, destacando como o conhecimento em questão é representado socialmente, ao se considerar a linha editorial da revista. Nesse sentido, a Superinteressante demonstrou-se fortemente associada à (re)produção do senso comum, intentando atrair a curiosidade do leitor, por meio da aproximação entre interlocutores.
\end{abstract}

Palavras-chave: Análise do Discurso; Divulgação Científica; Representações Sociais; Tabu; Superinteressante.

ABSTRACT: In this paper is inserted in the theoretical and methodological framework of Discourse Analysis of Scientific Communication and Social Representations Theory, seek to analyze the linguistic-discursive treatment of information, given by the Brazilian print media, on a thematic topic traditionally seen as taboo. To do so, we chose a news report published in the magazine Superinteressante, which deals with scientific knowledge around the curse. Subsequently, we describe and analyze linguistic-discursive strategies used by journalists in the process of recontextualization, highlighting how the knowledge in question is represented socially when considering the editorial line of the journal. In this sense, Superinteressante was shown to be strongly associated with the (re)production of common sense, trying to attract the curiosity of the reader, through the approach of interlocutors

Keywords: Discourse Analysis; Scientific Communication; Social Representations; Taboo; Superinteressante.

\footnotetext{
${ }^{1}$ Professor efetivo do Instituto Federal de Educação, Ciência e Tecnologia do Sul de Minas (IFSULDEMINAS); doutorando do Programa de Pós-Graduação em Desenvolvimento Humano e Tecnologias, na linha de pesquisa Tecnologias, Corpo e Cultura, pela Universidade Estadual Paulista (UNESP). E-mail: carlos.noccioli@ifsuldeminas.edu.br

${ }^{2}$ Professora Adjunto III da Universidade Federal de Viçosa - UFV. E-mail: cristiane.cataldi@ufv.br
} 


\section{Preliminares}

No intuito de analisar o tratamento linguístico-discursivo de informações sobre temas considerados tabu, referentes a questões sexuais que representam o homem e a mulher em nossa sociedade contemporânea ocidental, elegemos uma reportagem constante da seção Ciência da revista Superinteressante, intitulada "A Ciência do Palavrão", escrita pelos jornalistas Alexandre Versignassi e Pedro Burgos, a fim de verificarmos como o processo de recontextualização do discurso sobre ciência ocorre na mídia impressa brasileira. Mais especificamente uma ciência metalinguística ${ }^{4}$, no que tange ao trabalho aqui proposto, já que há uma peculiaridade do texto escolhido como corpus: sua relação intertextual com o que se propõe a analisar neste trabalho, designadamente uma abordagem acerca de recursos linguísticos consideradas tabu por seu caráter interdito em nossa sociedade, bem como as representações sociais às quais elas podem estar atreladas.

Ao selecionarmos a reportagem em questão, tivemos como foco as publicações na revista Superinteressante que abordassem uma temática considerada tabu acerca de aspectos relacionados à sexualidade. Identificamos e analisamos, a partir disso, as estratégias linguístico-discursivas que caracterizam o processo de recontextualização do discurso científico em discurso geral $^{5}$. Ou seja, as reflexões realizadas neste artigo giram em torno da transposição do discurso da esfera técnica para a esfera do público leigo.

Por essa razão, faz-se interessante analisar o tratamento linguístico-discursivo das informações de caráter científico na mídia impressa, materializada em nossa escolha na Superinteressante, a respeito de tópicos temáticos referentes a aspectos sexuais humanos, tradicionalmente vistos como tabu, uma vez que suscitam discussões polêmicas e, consequentemente, estratégias de reelaboração, em termos, não somente de intercâmbio de registro, mas também de modalização e adaptação do discurso, a fim de que se pondere com relação aos impactos que poderiam causar uma informação de caráter interdito em determinadas convenções sociais.

\section{Análise do Discurso da Divulgação Científica}

\footnotetext{
3 A reportagem analisada no presente trabalho pode ser acessada na íntegra por meio do seguinte link: https://super.abril.com.br/ciencia/a-ciencia-do-palavrao/

${ }^{4}$ Destaca-se uma peculiaridade do texto escolhido como corpus: sua relação intertextual com o que se propõe a analisar neste trabalho, designadamente uma abordagem acerca de recursos linguísticos consideradas tabu por seu caráter interdito em nossa sociedade, bem como as representações sociais às quais elas podem estar atreladas.

${ }^{5}$ Usando a terminologia "geral” em oposição à concepção de "técnico", "especialista".
} 
Ao considerar que a (inter)ação humana ocorre por meio da "palavra em movimento", a Análise do Discurso oferece subsídios teóricos para o estudo de textos, quer sejam orais, quer sejam escritos, "como produto do uso linguístico em situações concretas, nas quais se objetiva uma interação entre os interlocutores a partir de uma intencionalidade". (CATALDI, 2009, p. 48).

Segundo Calsamiglia e Cassany (1999), a Análise do Discurso é um campo de estudo interdisciplinar, que tem sua base sustentada por outras teorias linguísticas calcadas na linguagem em uso. Dessa forma, é pertinente e relevante o uso de seu aporte teóricometodológico para o estudo do discurso divulgativo. De acordo com Cataldi (2007):

Ainda que o discurso divulgativo utilize informações procedentes do discurso científico, o modo de elaboração deste novo discurso é específico, pois está determinado por concepções próprias de produção e de difusão. (CATALDI, 2007, p. 158).

Tornar acessíveis ao público leigo conhecimentos de caráter técnico e científico é uma tarefa árdua em uma sociedade contemporânea cada vez mais bombardeada por informações. Desde a década de 1980 observa-se um maior interesse pela divulgação científica, tanto no cenário nacional quanto no âmbito internacional (CATALDI, 2009). Esse contexto acarreta, segundo Cataldi (2007, p. 155), "a consideração da ciência como notícia”, ou seja, justamente por haver demanda pela (in)formação, a ciência passa a compor a pauta jornalística da mídia. Sendo os jornais e as revistas canais para o público em geral ter acesso às novidades do campo científico, Cataldi (2009, p. 44) considera esses veículos importantes fontes "de (in)formação sobre as implicações científicas e sociais do desenvolvimento tecnológico".

Recontextualização da Informação sobre Ciência

A difusão da ciência, em suas diversas modalidades, sejam elas escritas ou orais, envolve procedimentos de transformação, ou ainda, de reformulação das informações previamente produzidas por cientistas. Assim, diz-se que a divulgação científica é uma prática reformulativa geral em relação a elementos puramente referenciais e informativos procedentes do texto fonte. Todavia, esse processo de reelaboração não se restringe a apenas esses aspectos, acionando ainda questões relativas à emoção. 
Ciapuscio (1997) chama a atenção para o fato de que algumas características retóricas e linguísticas são prototípicas do texto científico, tais como vocabulário unívoco ${ }^{6}$ e preciso; referência escrita ao objeto e a tentativa de não utilização de marcas subjetivas; ausência de elementos emocionais; sintaxe simples, entre outras.

Os textos jornalísticos de divulgação científica consistem, portanto, em uma fonte de discurso público, constituídos por fatores contextuais atrelados à sua produção. Conforme Cataldi (2007), mesmo que o discurso divulgativo tenha o discurso científico como fonte, o modo de elaboração desse novo discurso é específico, haja vista sua dependência às concepções próprias de sua produção e difusão.

Nessa linha de raciocínio, a autora ainda postula que o processo de recontextualização do conhecimento científico é caracterizado como uma "re-criação" desse tipo de conhecimento para cada público específico. Entretanto, Cataldi chama a atenção para o fato de essa prática discursiva não ser simplesmente um resumo ou redução aleatória de dados científicos, mas sim uma habilidade em selecionar, reorganizar e reformular as informações de caráter técnico para leitores com interesses e objetivos diversos, no processo de compreensão dos fatos científicos. É, portanto, o texto divulgativo um tipo de discurso primário, baseado em textos secundários ${ }^{7}$ que vão se modificando, a depender da situação comunicativa. Isso gera a necessidade de "procedimentos, utilizados na mídia impressa a partir de um uso linguístico escrito" variáveis "segundo certos parâmetros contextuais, como a situação comunicativa, os propósitos de quem a realiza e as características dos destinatários". (CATALDI, 2009, p. 49).

Em termos de estrutura cognitiva do discurso de caráter científico, fica a cargo do divulgador a decisão acerca de qual "estratégia divulgativa" utilizar, consoante o propósito comunicativo: "O produtor pode utilizar procedimentos "léxico-semânticos" (sinonímia, paráfrase, definição, descrição, denominação, generalização etc.), “discursivos" (contextualização, modalização, etc.) e/ou "cognitivos" (analogias, metáforas, metonímias etc.)". (Ibidem). No que tange a este último procedimento, o mais comum é que se usem em discursos de divulgação científica representações conceituais calcadas em analogias com o cotidiano.

\footnotetext{
${ }^{6}$ Utilizamos, consoante Ciapuscio (1997), o termo "unívoco" no sentido de uma terminologia que não abarque mais de um significado e, consequentemente, não gere ambiguidades.

7 Usamos as terminologias "discurso primário" e "texto secundário", conforme Ciapuscio (1997), para quem "texto secundário" representa o intertexto subjacente a um discurso ao qual temos acesso, ou seja, o "discurso primário".
} 
Para tanto, a recontextualização das informações sobre ciência está diretamente relacionada com procedimentos concretizados por uso linguístico-discursivo específico. Esses procedimentos, na observância do interesse e da necessidade de informar um público amplo, heterogêneo e leigo, são recorrentes na mídia impressa, por meio de seu uso linguístico escrito. São recursos que variam conforme os parâmetros contextuais, tais como a situação comunicativa, os propósitos de quem produz o texto e as características de seu interlocutor.

\section{Estratégias Divulgativas}

Cassany e Martí (1998) utilizam o termo "estratégias divulgativas” para referirem-se a diferentes tipos de recursos ou procedimentos verbais que são usados nos textos, no intuito de tornar acessíveis ao público leigo os diferentes conceitos técnicos: "Trata-se de um conjunto variado de fenômenos linguísticos que engloba seleção da informação, organização da mesma, formulação discursiva, seleção léxica, tratamento tipográfico, etc.". ${ }^{8}$ (CASSANY; MARTÍ, 1998, p. 60).

Para efeito de sistematização esquemática no que se refere à relação entre estratégias linguístico-discursivas e texto de divulgação científica, Cassany e Martí (1998) apresentam uma proposta de organização das estratégias divulgativas em uma ordem teórica de aplicação. Não que esse esquema deva ser adotado rigidamente na prática pelo divulgador na composição do texto, mas seja uma recomendação que poderia elucidar uma sequência do processo de forma mais lógica.

Nessa proposta, o primeiro ponto, para o qual os autores chamam a atenção, é a decisão de utilizar ou não no discurso divulgativo o conceito técnico propriamente dito. Em caso afirmativo, Cassany e Martí (1998) destacam a dificuldade de se 'explicar' o conceito ao público leigo, sendo que, para tanto, o emissor poderia lançar mão desde recursos lexicais, como sinônimos, paráfrases e definições, por exemplo, até recursos discursivos, como contextualização e modalização.

É importante destacar que essas estratégias ocorrem a partir de diferentes combinações para resolver problemas locais que possam surgir ao longo de todo texto:

\footnotetext{
${ }^{8}$ Tradução livre para: "Se trata de un conjunto variado de fenómenos lingüísticos que abarca cuestiones de selección de la información, organización de la misma, formulación discursiva, selección léxica, tratamiento tipográfico, etc".
} 
É importante que se leve em conta que é provável que em um mesmo texto devam ser tomadas várias vezes e em momentos distintos decisões diferentes sobre se usar ou não um conceito e com que recursos expressivos ${ }^{9}$ (CASSANY e MARTÍ, 1998, p. 60).

Sendo assim, a primeira estratégia a ser utilizada pelo divulgador seria evitar o conceito técnico, abstendo-se de uma terminologia especializada, trazendo-a para um nível geral, por meio de léxico comum e compreensível ao público leigo. Essa estratégia serviria para manter um baixo grau de especificidade e privilegiar a formalidade do discurso divulgativo.

As estratégias lexicais remetem às escolhas de termos gerais, bem como de outros recursos denominativos que são usados para designar conceitos. A utilização desses recursos permite-nos observar até que ponto os textos divulgativos elegem a terminologia técnicocientífica ou dão preferência para outras denominações mais comuns, como sinônimos genéricos ou paráfrases.

Cassany e Martí (1998) incluem também nessa descrição os diferentes recursos verbais de nível supraoracional, que não estão diretamente ligados à terminologia. Esses recursos afetam a seleção da informação, bem como a sua estruturação em sequências discursivas e a modalização do discurso.

Dessa forma, segundo os autores, quando o divulgador opta pela utilização do conceito científico em seu texto divulgativo, com efeito, será necessário um alto grau de contextualização, ou seja, contextualiza-se cognitivamente dado conceito, a fim de que este sirva de base para o desenvolvimento do texto. O procedimento consiste em se promover uma construção prévia do conhecimento para que o leitor possa situar esse conceito quando este (re)aparecer no texto. Conforme Cassany e Martí (1998), do ponto de vista textual, esse recurso consiste na utilização de microestruturas camufladas em definições de conceitos novos. De forma geral, essas estruturas poderiam ser concebidas em três fases progressivas: a exposição de dados que o autor pressupõe que o leitor conheça; a apresentação do conceito por meio de paráfrases ou de denominações que pertençam a um registro comum; e a apresentação do termo técnico específico.

\footnotetext{
${ }^{9}$ Tradução livre para: "Cabe tener en cuenta que es muy probable que en un mismo documento deban tomarse varias veces, en momentos distintos, decisiones diferentes sobre si usar o no un concepto y con qué recursos expresivos".
} 
Ainda na proposta de Cassany e Martí (1998, p. 64), uma outra "estratégia discursiva consistiria em 'narrativizar' a 'explicação' do conceito de natureza técnica ou inseri-lo em inúmeras características linguísticas típicas de gêneros narrativos" ${ }^{\prime 10}$. Por essa perspectiva, o leitor é capaz, mesmo em construções tidas como sintaticamente impessoais, perceber certo caráter de agentividade nos fatos "narrados", cujas sequências informacionais apresentam protagonistas que encabeçam ações, desenvolvidas em um tempo e espaço definidos. Esses elementos são típicos de sequências narrativas, inscrevendo o leitor em um universo que pode, inclusive, remetê-lo ao fantástico, ao popular.

A terceira estratégia discutida pelos autores, na esteira do nível supraoracional, é a modalização do discurso. Esse procedimento se concretiza a partir da exposição de marcas subjetivas emitidas por intermédio de juízos de valor, opiniões, apreciações, que acabam por evidenciar o ponto de vista do autor. Cassany e Martí (op. cit.) destacam como marcas da modalização discursiva a seleção lexical, a seleção sintática, o uso de advérbios enfáticos, bem como os modalizadores gerais do discurso.

Os autores acrescentam a esses procedimentos as perguntas retóricas, as quais foram observadas por eles com notória relevância em textos científicos que compunham o corpus de análise da pesquisa (1998). ${ }^{11}$

Considerando-se que algumas estratégias (como a narrativização, a contextualização dos conceitos técnicos e a modalização) são típicas do âmbito mais geral e que o texto de divulgação científica é formado por variados discursos, podemos dizer que essas estratégias seriam características do texto divulgativo propriamente dito, já que não seriam exclusivas de nenhum dos discursos que o compõem. Normalmente em textos de registro técnico-científico, ou mesmo em certos gêneros textuais (como artigos científicos) em que se formulam conhecimentos, podem ser encontrados:

\footnotetext{
${ }^{10}$ Tradução livre para: "estrategia discursiva consiste en 'narrativizar' la 'explicación' del concepto técnico o en introducir en ella numerosos rasgos lingüísticos típicos de los géneros narrativos".

${ }^{11}$ A bibliografia a que me refiro é acerca do artigo publicado na revista espanhola Quark, em que os autores em questão resumem um trabalho sobre publicações da imprensa espanhola no período de março a abril de 1996. Os autores se propuseram a descrever os diferentes recursos verbais utilizados por profissionais da divulgação científica na difusão de temas relacionados ao conceito "prion". Foram analisados por eles 94 textos em castelhano e catalão, publicados nos jornais La Vanguardia, El País, ABC, Avui, El Mundo e El Periódico de Catalunya, entre outros que compreendiam uma gama de gêneros periodísticos, além de trabalhos científicos semiespecializados, tais como Salud y Medicina do El Mundo, (de 28 de março de 1998) e Salud y Ciência do La Vanguardia (de 30 de março de 1998).
} 
discursos objetivos, neutros e carentes de expressões subjetivas, buscando uma estruturação mais lógica, não narrativa, enquanto que na divulgação, aparecem elementos modalizadores, construções narrativas e perguntas retóricas ${ }^{12}$ (CASSANY e MARTÍ, 1998, p. 66).

Portanto, o texto cujo caráter é divulgativo tende ao emprego de recursos expressivos próximos do senso comum: evitando-se termos técnicos, valendo-se de tipos narrativos, modalizando-se o discurso, utilizando-se variadas expressões e paráfrases de textos complexos. Dessa forma, consegue-se discorrer sobre dados teóricos, altamente abstratos e técnicos, de forma que esses possam ser compreendidos por leigos.

Assim, o processo de divulgação da informação - abrangendo desde a coleta de informações selecionadas para serem organizadas até a reformulação do discurso - presta-se a um grande número de estratégias comunicativas. Nesse sentido, a divulgação não seria uma "tradução", mas a produção de um novo discurso, construído a partir de outro ponto de vista.

Uma vez que deve-se ter claro para qual público determinado saber se destina, a título de exemplificação, Calsamiglia (1997) desenha o perfil do protagonista da divulgação. Faz-se necessário, primeiramente, imaginar o nível de conhecimento sobre o assunto, para que o divulgador possa decidir sobre o que deve ser dito e o que não deve ser.

No texto de divulgação, o conhecimento já pré-existente do interlocutor e os novos conhecimentos trazidos pelo divulgador devem ser dosados em um equilíbrio constante. Essa é uma questão crucial que se refere à dimensão cognitiva intrínseca à compreensão e à inteligibilidade do texto de divulgação. Recursos linguísticos e discursivos para assegurar esse processo são muitos e variados.

Nessa perspectiva, o divulgador não é um conduto ${ }^{13}$ de transmissão neutro, mas um criador de novos significados que pode articular de forma contextualizada o conhecimento científico ao grande público. Cabe ao divulgador integrar novos conhecimentos ao processo de construção cultural que ocorre no contexto da vida cotidiana.

Vale ressaltar que, segundo Ciapuscio (1997), a produção do texto científico implica uma reelaboração de conteúdo científico, com fidelidade conceitual e modal, para o leitor leigo não apenas se informar, mas também se interessar pelos temas científicos. Daí se considerar a divulgação científica como uma tarefa de grande desafio intelectual.

\footnotetext{
12 Tradução livre para: "discursos objetivos, neutros y carentes de expresiones subjetivas, que buscan una estructuración lógica no narrativa, mientras que en la divulgación aparecen elementos modalizadores, construcciones narrativas y preguntas retóricas".

${ }^{13}$ Referência ao texto A metáfora do Conduto, de Michael Reddy (2000).
} 
Segundo ainda destaca a autora, para que o objetivo informativo do texto fonte seja transformado em objetivo (in)formativo e persuasivo - sobre a relevância ou interesse de dada descoberta ou desenvolvimento científico -, é necessário acuidade com relação à composição e à estruturação do texto de divulgação. Essa observação refere-se inclusive à composição de títulos que, muitas vezes, remetem a interpretações distintas do verdadeiro fato em questão, simplesmente objetivando despertar o interesse do público.

Nesse sentido, para despertar o interesse do leitor, existem distintos recursos típicos dos textos de divulgação, tais como humor, jogos de palavras, alusões a elementos do mundo cotidiano, possivelmente observáveis na Revista Superinteressante.

É preciso lembrar que diante desse enfoque linguístico-discursivo, o processo de recontextualização - composto de um rico arsenal de artifícios linguísticos e cognitivos intrínsecos ao próprio processo - demonstra a pluralidade de pontos de vistas capaz inclusive de formar a opinião do público em relação a, por exemplo, como abordar temas sobre a sexualidade, considerando-se a diversidade de vozes que expressam visões de mundo submetidas à reformulação de um novo locutor. Dessa forma, torna-se possível a identificação de representações sociais que expressam a visão de mundo não apenas da linha editorial da Superinteressante, mas da sociedade de nosso tempo, já que a revista pode, além de formar opiniões, reproduzir discursos do senso comum.

Teoria das Representações Sociais

Embora seu germe tenha sido na Sociologia, com significativa presença na Antropologia e na história das mentalidades, o conceito de representação social tem uma dimensão interdisciplinar que ganha status de teoria na Psicologia Social, superando um ou outro domínio das áreas de humanas, servindo de proficiente ferramenta para campos diversos, inclusive, no âmbito da linguagem.

Arruda (2003) apresenta um panorama da Teoria das Representações Sociais sob a perspectiva psicossocial, promovendo um elo entre essa abordagem e as teorias feministas de gênero. Sendo a psicologia social responsável pelo estudo acerca da relação entre indivíduo e sociedade, ao associar-se a isso uma preocupação cognitiva, poder-se-iam, com efeito, obter reflexões em torno (i) da construção do conhecimento pelo indivíduo, pelo grupo, ou pelo ser social, a partir de aspectos, sobretudo, sociais e culturais, e em torno (ii) da maneira pela qual 
a sociedade conhece e constrói esse conhecimento com os indivíduos. Assim, a Teoria das Representações Sociais apresenta-se como eficiente aporte teórico no que diz respeito à análise de tabus, sobretudo os que se referem a universos sexuais masculino e feminino.

Uma Particular Representação Social: o Tabu

Os primeiros registros sobre a noção de tabu foram feitos por um navegante inglês chamado James Cook, em viagem à Oceania. Denominado pelos nativos das Ilhas Tonga por Tapu - anglicizado pelo capitão por taboo, permitindo a forma em português tabu -, a expressão designava tudo aquilo que era sagrado e ao mesmo tempo proibido. Portanto, o “'tabu' traz em si um sentido de algo inabordável, sendo principalmente expresso em proibições e restrições". (FREUD, 1975, p. 32) ${ }^{14}$.

Como um tabu é designado a partir de uma temática - incluindo-se desde um determinado assunto até determinada conduta ou comportamento - interdita em certa sociedade, observa-se a relevância de aspectos sociais e culturais para sua interdição. Se essa ordem do "evitado" remete a razões que interferem, de algum modo, na sensibilidade das pessoas, ou atentam contra a moral de dada sociedade, os temas considerados tabu estão atrelados a questões variáveis entre grupos sociais, inevitavelmente sujeitos a representações sociais de um determinado povo. A partir disso, podemos compreender as representações sociais de um povo como um conjunto de "regras" que regem o comportamento de dada sociedade, inerente ao processo de sociabilidade de cada indivíduo.

Augras (1989, p. 33) explica a contribuição de Lévi-Strauss no que se refere à constituição dessas "regras sociais". Segundo a autora "em cada sociedade, as crianças aprendem, desde o nascimento, como sua cultura representa o mundo, e quais são as regras de comportamento dentro dele", configurando-se o sentido do termo "socialização". A socialização é, no âmbito das representações e valores, capaz de transformar "regras de conduta e representações do mundo em vivências individuais". Nesses termos, a realidade que o ser humano constrói dá-se em conjugação com a sociedade e "é no significado que cada

\footnotetext{
${ }^{14}$ Na obra intitulada Totem e tabu, cuja primeira edição data de 1913, Freud faz uma contribuição à antropologia social, através de reflexões que o levam a hipóteses acerca da origem das instituições sociais e culturais, bem como da religião e da moralidade.
} 
grupo atribui aos elementos que compõem seu mundo que devemos buscar a compreensão" do tabu (AUGRAS, 1989, p. 34).

Compreender o tabu de cada cultura implica, portanto, a observância dos comportamentos ideológicos geridos por cada sociedade. Vilaça (2009, p. 53) exemplifica essa observância por meio dos conceitos de "decente" e "indecente", os quais "são socialmente aprendidos". Além disso, segundo a autora, "não há cultura que não tenha seu conceito de decência", já que os comportamentos são atributos do campo ideológico.

Sob essa ótica, o corpo humano, ou mesmo o sistema biológico humano que o integra, está sujeito à representação da própria espécie, à luz de fatores sociais e culturais (RODRIGUES, 1983). Portanto, é importante observar essas representações no campo da linguagem, dado que as "formas linguísticas estigmatizadas e de 'baixo prestígio', condenadas pelos padrões culturais" (PRETI, 1984, p. 3) tendem a sofrer algum tipo de variação, associada ao contexto de produção a que estão veiculadas - em nosso foco de análise particular, a divulgação científica de temas considerados tabu atrelados às genitálias humanas.

Poderíamos, a partir disso, conceber que a representação social é uma ação simbólica que, além de nortear o mundo, facilita sua compreensão, já que "tem um caráter cognitivo e autônomo e configura a construção social da realidade" em via de mão-dupla entre ação e comunicação (ARRUDA, 2003, p. 142). Em nosso trabalho, cujo interesse reporta-se a uma análise de textos de divulgação científica, destaca-se a necessidade de um complemento teórico que possa subsidiar questões referentes a representações no plano da sexualidade masculina e feminina, entendidas como tabu.

Considerando o aporte teórico da Teoria das Representações Sociais, pode-se dizer que esse construto teórico é um valioso instrumento de conhecimento acerca de dada sociedade, não copiando nem refletindo fielmente a realidade, mas interpretando-a com base no olhar do observador. Sob esse viés, é natural que se identifiquem, nos discursos considerados tabu de uma revista, como a Superinteressante, não apenas as ideologias que partem da linha editorial da revista, mas também a reprodução de discursos do senso comum.

Reportagem em Análise

$\mathrm{Na}$ reportagem "A ciência do palavrão", constante da seção Ciência, os jornalistas Alexandre Versignassi e Pedro Burgos constroem um texto expositivo-argumentativo acerca 
do "palavrão", demonstrando algumas questões envolvidas quando da sua utilização. O texto aponta para questões que vão desde aspectos biológicos, como a participação do cérebro na produção do palavrão, até as reflexões do âmbito da linguística e as relações desse tipo de léxico com as representações sociais de dadas sociedades em certas épocas.

Embora, a princípio, o conhecimento a ser divulgado esteja atrelado ao âmbito das ciências humanas, observa-se que, em grande parte do texto, expõem-se questões fisiológicas/biológicas, tais como patologias cerebrais e funcionamento orgânico quando da produção do palavrão, corroborando com o senso comum na manutenção do estereótipo do caráter científico, como mais vulgarmente identificável às ciências naturais.

Considerando-se o subtítulo da reportagem - "Os xingamentos mostram a evolução da linguagem, das sociedades e, de quebra, ajudam a desvendar o cérebro" -, espera-se que o texto apresente "os xingamentos" pelo viés da "evolução da linguagem" e "das sociedades" e também a partir dos aspectos biológicos envolvidos no cérebro. Isso poderia indicar um texto que discorresse sobre (i) discussões linguísticas atreladas às representações sociais e, ainda, (ii) algumas questões sobre o funcionamento do cérebro no que diz respeito ao uso do palavrão. Explícito na expressão "de quebra”, poder-se-ia inferir que a discussão biológica não seria o foco do texto.

Não obstante, o que se verifica - desde o primeiro parágrafo depois do lead, que responde às suas perguntas retóricas - é que a discussão introdutória do texto tange às ciências naturais, já que os jornalistas abrem as discussões acerca do palavrão, evocando pesquisas que demonstram o "nascimento" do palavrão em determinada região cerebral.

No lead, duas perguntas retóricas, conforme em (1) e (2), e uma situação evocada do cotidiano, como em (3), provocam a interatividade com o leitor. Em (4), o marcador discursivo "Pois é", acende as discussões que se iniciam desde o segundo parágrafo e que serão abordadas ao longo do texto:

(1) Por que diabos "merda" é palavrão?

(2) Aliás, por que a palavra "diabos", indizível décadas atrás, deixou de ser um?

(3) Outra: você já deve ter tropeçado numa pedra e, para revidar, xingou-a de algo como "filha-da -puta", mesmo sabendo que a dita nem mãe tem. 
(4) Pois é: há mais mistérios no universo dos palavrões do que o senso comum imagina. $\left(\right.$ destaque nosso $\left.{ }^{15}\right)$

Em uma perspectiva metalinguística, proposta pela própria reportagem, a questão posta em (1) leva à reflexão da segunda pergunta retórica em (2). Em (3) a ponderação vai da metalinguagem à cumplicidade com o leitor, buscando seu conhecimento de mundo para as possíveis explicações posteriores. É o caso de (4), que, por meio do marcador discursivo "Pois é", dá início às discussões, sintetizadas em forma de paráfrase da consagrada máxima de Shakespeare, em sua peça Hamlet: "Há mais mistérios entre o céu e a Terra do que supõe a nossa vã filosofia".

Segundo os jornalistas, a solução - explicação - para "os mistérios no universo dos palavrões" estaria na ciência: "Mas a ciência ajuda a desvendá-los". Sobre essa ciência, a referência inicial é a ciência natural (5) e prossegue-se nesse âmbito, recrutando-se mais validações da esfera científica biológica (6). Nota-se que somente a partir desses primeiros argumentos é que insurgem discussões atreladas à psicologia (7): cérebro".

(5) "Pesquisas recentes mostram que as palavras sujas nascem em um mundo à parte dentro do

(6) A medicina ajuda a entender isso.

(7) É o que pensa o psicólogo cognitivo Steven Pinker, da Universidade Harvard.

Outra perspectiva latente no texto refere-se às reflexões que giram em torno dos palavrões relacionados às representações sociais (8). A partir disso começa-se a estabelecer relações com aspectos linguísticos (9), nomeadamente a representação social atrelada a uma expressão, por força de um possível significado negativo que ela poderia abarcar:

(8) Pegar mulheres à força permitia que um macho fizesse dezenas, centenas de filhos, coisa que contou pontos no jogo da evolução. Já para as mulheres isso é o inferno. mal".

(9) Daí foi natural que a expressão "foder alguém" virasse sinônimo de "fazer um grande

Destaca-se em (8) a utilização pelos jornalistas do termo "macho", em vez da palavra "homem", para oposição ao termo "mulheres". Essa opção lexical revela a nuança de

\footnotetext{
${ }^{15}$ Os negritos marcados no corpus são todos nossos, utilizados aqui como ferramenta metodológica de análise.
} 
virilidade impregnada no ato de "pegar à força" uma parceira sexual. Dessa forma, podemos depreender um caráter conservador da revista, que, por meio dessa denominação, reproduz o estereótipo de masculinidade comum em nossa sociedade. Outros exemplos ilustram o elo entre as representações sociais e a questão linguística, como podemos visualizar em (10), (11), (12), (13) e (14):

(10) A coisa é tão arraigada que até uma palavra inocente hoje, como "coitado" ou "tadinho", sua variante mais fofa, significa "aquele que sofreu o coito".

(11) "Que se dane!", “diabos" ou "vá para o inferno" já foi algo mais impactante. Claro: até décadas atrás não havia prognóstico pior que não ir para o céu quando morresse.

(12) Outra: quando "câncer" era sinônimo de morte, também não podia ser dita livremente. Nos obi- tuários, a pessoa não morria de câncer, mas de "uma longa enfermidade".

(13) "Que a peste invada as casas de ambos!" Uma baita ofensa no século 16, quando a peste bubônica ainda era uma ameaça na Europa. Mas agora, no mundo limpo e cheio de antibióticos que a gente conhece, o xingamento shakespeariano parece inócuo.

(14) Mais uma mostra de como os palavrões flutuam com o espírito do tempo são as expressões que são tabu num lugar e não têm nada de mais em outro.

Em (10), evidenciam-se representações sociais sobre sexo em nossa cultura. $\mathrm{Na}$ metalinguagem exposta sobre o significado da expressão "coitado", "sofrer o coito" abarcou apenas o significado negativo da ambivalente concepção sobre sexo. Apesar disso, tanto em (11) quanto em (12) e (13), as noções sobre tabu são mais gerais, ou seja, extrapolam compreensões relacionadas apenas ao sexo para demonstrar o valor social que certas questões poderiam representar, quando concebidas como "desgraça" em determinada época. Em (14), a informação divulgada conclui as relações que existem entre uma "desgraça" e a representação de um termo ou expressão como tabu.

Finalmente, partindo dessa perspectiva das representações sociais, os jornalistas atingem, em definitivo, o âmbito linguístico, à guisa de uma conclusão para o texto, como se procede em (15):

(15) "Isso depende dos mecanismos de conservação da língua, que são o ensino, os meios de comunicação e os dicionários. As palavras relacionadas a sexo que não são palavrões são quase todas da literatura científica, como pênis e ânus", explica a lingüista Wânia de Aragão, da Universidade de Brasília. 
Em (15), observa-se a seleção lexical estreitamente associada à Linguística nas expressões "mecanismos de conservação da língua", "ensino" e "meios de comunicação e os dicionários", validadas pelo argumento de autoridade de uma linguista. No discurso direto de Wânia de Aragão, chama-se a atenção para o fato de que as palavras que designam questões associadas ao sexo, e não são palavrões, pertencem à literatura científica.

Como se supõe em um texto de finalidade divulgativa, quer seja na área das ciências humanas, quer seja na área das ciências naturais, sobretudo em um veículo de conformação almanaquista, parte do conhecimento exposto advém como consequência de perguntas retóricas, assim como já expusemos nos exemplos em (1) e (2).

$\mathrm{Na}$ esteira dessa retórica, a maioria das perguntas realizadas no texto simulam uma interatividade com o leitor. Como se observa em (16), (17), (18), (19) e (20), as perguntas realizadas são, em seguida, respondidas pelo próprio locutor, ou na voz de uma autoridade:

(16) Os palavrões, por esse ponto de vista, são poesia no sentido mais profundo da palavra. Duvida?

(17) Coincidência? "Não. Não é por acaso que as substâncias que mais dão nojo também sejam vetores de doenças. [...].

(18) Afinal, sexo é bom, não? Não necessariamente.

(19) Mas espera aí: como algo tão barra-pesada vira uma palavra até bonitinha? É o que vamos ver.

(20) Mas quem decide o que é palavrão e o que não é? "Isso depende dos mecanismos de conservação da língua, que são o ensino, os meios de comunicação e os dicionários. As palavras relacionadas a sexo que não são palavrões são quase todas da literatura científica, como pênis e ânus", explica a lingüista Wânia de Aragão, da Universidade de Brasília.

Em (20) a "resposta" à pergunta é apresentada a partir de um argumento de autoridade validado na voz de uma professora da Universidade de Brasília. As perguntas retóricas, nesse texto, cumprem a finalidade de introduzirem as novas informações a serem divulgadas, em um esquema que garante a progressão do texto. Especificamente em (16) a pergunta “Duvida?" é o intróito de um exercício interativo de reflexão proposto pelos jornalistas em (21):

(21) Então pense em uma palavra forte. "Paixão", por exemplo. Ela tem substância, sim, mas está longe de transmitir toda a carga emocional da paixão propriamente dita. 
$\mathrm{Na}$ mesma expectativa divulgativa, a interatividade e a inclusão do leitor no texto, mesmo que de forma simulada, remetem a construções que se assemelham a interações face a face, observáveis por intermédio de marcadores discursivos típicos da oralidade, como nos exemplos seguintes:

(22) Duvida?

(23) Coincidência?

(24) Mas espera aí: como algo tão barra-pesada vira uma palavra até bonitinha? É o que vamos ver.

(25) Veja só.

Nesse sentido, em (25) observa-se que gramaticalmente o verbo "ver" é apresentado no modo imperativo. É sabido que sua função textual ultrapassa a questão puramente gramatical do verbo, exercendo um papel discursivo de interatividade com o leitor, a partir da expressão "Veja só". Ao se buscar essa interação, a função fática da linguagem pode ser expressa pela utilização dos verbos em modo imperativo, que ora prepara o leitor para a inserção de uma informação nova, como em (26), ora incita-o à realização de algum exercício de reflexão, conforme exposto em (21) e ainda observável em (27) e (28):

(26) Veja o caso da síndrome de Tourette.

(27) Para entender isso melhor, complete a frase "João Maria" $[\ldots]$.

(28) Note que a origem de "fodido" e seus equivalentes não envolve o sexo [...].

Em (27) e (28), a reflexão sobre um aspecto linguístico parte de um didatismo dos jornalistas, a fim de que se compreenda a relação das representações que se fazem sobre sexo e o desenvolvimento de um palavrão.

Outro recurso é a evocação da cumplicidade do leitor, expressa ainda na função apelativa da linguagem, concretizada por um procedimento de inclusão do leitor, como em (29) e (30), de pergunta retórica, como em (31), ou representação de indeterminação do sujeito, por meio de termo nominal, como em (32):

(29) Mas você não precisa ter lesão nenhuma para se descontrolar de vez em quando, claro. 
(30) E colocou em números cientificamente rigorosos [...] aquilo que você já sabia [...]

(31) Afinal, sexo é bom, não?

(32) Mas agora, no mundo limpo e cheio de antibióticos que a gente conhece [...]

A cumplicidade com o leitor aliada à tentativa de levá-lo a uma reflexão, para que o conhecimento em questão se torne mais inteligível, aparece no texto por meio de uma estratégia divulgativa que se refere à utilização de analogias com fatos corriqueiros. Dessa maneira, uma situação hipotética é levantada, no intuito de que o leitor possa compreender o conhecimento enfocado, por meio de um exemplo mais próximo de seu cotidiano:

(33) [...] você já deve ter tropeçado numa pedra e, para revidar, xingou-a de algo como "filhada -puta", mesmo sabendo que a dita nem mãe tem.

(34) Se você xingar alguém gratuitamente e o sujeito não ficar bravo, significa que ele é seu amigo.

(35) Se você fosse excretar alguma dessas coisas na rua, essa também seria a ordem de impacto nas outras pessoas $[\ldots]$ $\operatorname{com} \ldots$

(36) [...] você pode dizer que João fez amor com Maria, dormiu com, fez sexo com, transou

(37) Se você for a Portugal, vai ver que eles preferem cu e rabo para referirem-se às nádegas $[\ldots]$

O texto como um todo é revestido do registro informal, remetendo à já mencionada interação face a face e quebrando a rigidez peculiar do discurso científico. Em vista desse processo de divulgação do conhecimento, destacam-se construções que tangem a conversas descontraídas de caráter informal, tais como:

(38) Isso mostra que, sem o gânglio basal para tomar conta, o sistema límbico se solta todo.

(39) Timothy Jay sabe do que está falando. É um expert em palavrões.

Em (39) observa-se que, como estratégia divulgativa, os jornalistas recontextualizam um argumento de autoridade na forma de uma construção popular para validação do discurso. Estratégia semelhante é utilizada em forma de analogia com “jogos” para explicação da teoria darwiniana: 
(40) Pegar mulheres à força permitia que um macho fizesse dezenas, centenas de filhos, coisa que contou pontos no jogo da evolução.

Outros exemplos da utilização do registro informal podem ser observados nos trechos a seguir:

(41) Com os palavrões, a história é outra.

(42) [...] a coisa mudou de figura, e câncer, apesar de ainda dar calafrios, virou uma palavra bem mais corriqueira.

(43) E também há o inverso: palavras normais que viram tabu. Em algum momento da história do português um sujeito chamou pênis de "pau". E uma palavra originalmente "pura" enveredava para o mau caminho.

(44) A palavra "esquizofrênico", por exemplo, nasceu na ciência, mas agora, com o aumento dos diagnósticos de doenças mentais, caiu na boca do povo.

(45) Mas saber quais serão os palavrões do futuro é tão impossível quanto prever o futuro [...] do Corinthians.

Em (45), a iniciativa de levar o conhecimento mais abstrato ao domínio mais corriqueiro fica patente no chiste com um dos mais populares times de futebol do Brasil, tradicionalmente criticado pelos torcedores de outras equipes.

Uma vez que estamos tratando de aspectos do texto que se referem à oralidade, não poderíamos deixar de mencionar marcadores discursivos tais como "daí", que aparece em (46) e (47), e expressões de forma geral que simulam a interação face a face, como em (48) (49) (50) (51) (52) e (53):

(46) Daí que grupos de homens adoram usar cumprimentos como "Fala, cuzão!"

(47) Daí foi natural que a expressão "foder alguém" virasse sinônimo de "fazer um grande mal".

(48) Não é à toa.

(49) Veja só.

(50) Coincidência? "Não. [...].

(51) Mas com um grande e gordo "puta que o pariu" a história é outra.

(52) Mas espera aí: como algo tão barra-pesada vira uma palavra até bonitinha? É o que vamos ver.

(53) Outra: quando "câncer" era sinônimo de morte, também não podia ser dita livremente. 
Outros recursos importantes para a quebra da formalidade são a adjetivação (54) (55) (56) (57) (58) (59) (60), a expressão com valor de adjetivo (61), a intensificação por alguma expressão de valor adjetivo, como exposto em (14), ou o valor adverbial, visualizável em (61), (62) e (63), ou mesmo o uso de verbo (64). Trata-se de recursos os quais, embora pareçam construções que remetam a algum tipo de juízo de valor, na verdade são estratégias para tornar a informação mais acessível, como se observa nos excertos a seguir:

(54) Mas o sistema límbico é burro. Burro e sincero.

(55) Mas com um grande e gordo "puta que o pariu" a história é outra.

(56) Traduzindo: palavrões são f*.

(57) Tão f* que nem os usamos só para xingar.

(58) Já para as mulheres isso é o inferno.

(59) [...] a violência sexual dentro dos presídios está aí para provar. A coisa é tão arraigada que até uma palavra inocente hoje, como "coitado" ou "tadinho", sua variante mais fofa, significa "aquele que sofreu o coito".

(60) Mas espera aí: como algo tão barra-pesada vira uma palavra até bonitinha? É o que vamos ver.

(14) Mais uma mostra de como os palavrões flutuam com o espírito do tempo são as expressões que são tabu num lugar e não têm nada de mais em outro. inferno.

(61) Então, quando a ideia era insultar para valer, nada melhor que mandar alguém para o

(62) O papel delas é ter poucos, e bons, filhos. Então selecionar o pai é fundamental, e engravidar de alguém que a violentou, um baita prejuízo.

(63) Uma baita ofensa no século $16[\ldots]$

(64) Se você for a Portugal, vai ver que eles preferem cu e rabo para referirem-se às nádegas, e que coram quando alguém fala "broche" (o termo sujo para sexo oral).

No que se refere aos adjetivos empregados em (56) e (57), destaca-se a utilização de uma gíria ("foda”), cuja base é o próprio palavrão. O exercício metalinguístico provoca humor, uma vez que o uso da expressão pelos jornalistas exemplifica como a expressão é rotineiramente aplicada. Curiosamente, há uma "censura" à expressão, com a utilização do 
asterisco. Entretanto, a palavra - e suas derivações gramaticais - que, em seu sentido mais básico, ainda que considerado chulo, remete à relação sexual, aparece no texto mais três vezes e sem nenhum tipo de interdição:

(65) [...] "foda" e "merda" (ou "fuck" e "shit") correspondem à metade de todos os palavrões ditos - sem contar suas variantes.

(66) Daí foi natural que a expressão "foder alguém" virasse sinônimo de "fazer um grande mal".

(67) Note que a origem de "fodido" e seus equivalentes não envolve o sexo apenas como uma ferramenta de submissão de homens contra mulheres.

A diferença do emprego em (56) e (57) para (65) (66) e (67) reside no fato de que, nestes últimos, a aplicação é metalinguística, ou seja, usam-se as expressões com a cabível "licença científica", por elas constituírem corpus da exposição e exemplificação da pesquisa. Em (56) e (57) o emprego das expressões fica a cargo dos jornalistas, não mais sendo objeto de estudo, mas parte integrante da linguagem do texto. Nessa perspectiva, um texto que, por um lado, tenta abordar cientificamente uma questão considerada tabu, por outro, ratifica a representação social do palavrão como algo impronunciável, ou agente desestabilizador dos bons costumes.

Para finalizar essa análise linguística geral do texto, é importante destacar os trechos em que os jornalistas tecem considerações sobre o caráter "tabu" de certas palavras, como exposto em:

(14) Mais uma mostra de como os palavrões flutuam com o espírito do tempo são as expressões que são tabu num lugar e não têm nada de mais em outro.

(43) E também há o inverso: palavras normais que viram tabu. Em algum momento da história do português um sujeito chamou pênis de "pau". E uma palavra originalmente "pura" enveredava para o mau caminho.

Em (14), destacam-se as variações temporais e regionais como condição sine qua non para dada sociedade considerar uma palavra "normal" como tabu. O acaso da constituição do palavrão é sinalizado pela história hipotética em (43). Assim, nesses trechos, podemos observar que os jornalistas chamam a atenção para o caráter estritamente atrelado à representação de cada época para a concepção de uma expressão como tabu. 
Síntese da Análise

Podemos constatar que a revista promove a aproximação entre a informação técnicocientífica e as concepções típicas das relações sociais habituais, divulgando e, ao mesmo tempo, fomentando a curiosidade em relação ao conhecimento que envolve os aspectos sexuais humanos.

Assim, é possível se observar que o tema, atrelado a um universo tabu, relativo a questões sexuais, é concebido no espaço ideológico da revista por meio de matizes jocosas. Ou seja, os temas que comumente são encarados sob o viés do interdito refletem, na revista Superinteressante, as características de seu público leitor: a subversão dos valores tidos como tabu, frequentemente abordado com finalidade chistosa no grupo social dos jovens.

Recrutam-se estratégias para que as informações específicas do campo científico atinjam um interlocutor inscrito no quadro do público geral, de modo que não apenas a acessibilidade da informação seja promovida, mas também que o público leitor possa ter seu interesse despertado pela revista.

Podemos perceber que a reportagem analisada divulga dados científicos de um conhecimento corriqueiro em nossa cultura - o palavrão. Contudo, esse conhecimento é concebido em forma de tabu, expressando a representação social sobre os palavrões - tanto por meio do julgamento dos jornalistas quanto por meio de discursos científicos atribuídos a especialistas.

Embora o texto analisado esteja revestido da intenção de desmitificar o senso comum, ou, no mínimo, tratar de informações científicas, a Superinteressante (re)produz representações sociais em nossa sociedade contemporânea ocidental. Isso ocorre ou por uma questão mercadológica, no intuito de atrair o público consumidor - os jovens -, ou por mera dificuldade de desvinculação do senso comum; a Superinteressante, dessa forma, aproxima-se do discurso geral e, mais especificamente, do universo jovem.

Como estratégia divulgativa, nessa reportagem, os jornalistas valem-se de um registro informal, na busca por uma interatividade com o leitor. Para tanto, aproveitam-se do que o próprio tema pode-lhes oferecer: uma maior proximidade entre os locutores peculiar à linguagem considerada como palavrão. 
A partir de uma linguagem coloquial, utilizada para melhor interagir com seu público leitor, a revista Superinteressante promoveu uma série de referências intertextuais com ditos populares e clichês, demonstrando sua forte associação à (re)produção do senso comum. Nesse sentido, a reportagem intenta atrair a curiosidade do leitor, buscando uma relativa adequação à situação comunicativa: divulgar o conhecimento em pauta pela estratégia da aproximação entre interlocutores e pelo viés da curiosidade de construções cômicas.

As estratégias de reelaboração tecidas pelos jornalistas fazem referências desde ao intercâmbio de registro até à modalização e à adaptação do discurso, mesmo que isso não tenha a finalidade de ponderar acerca dos impactos que poderiam causar uma informação de caráter interdito em determinadas convenções sociais, mas sim de propiciar um efeito perturbador contrário.

Desse modo, no que se refere à linguagem da revista, o registro é, em grande parte, informal, comportando traços típicos da oralidade, evidenciado por meio dos marcadores discursivos que exercem importante função interativa, amarrando o texto no plano cognitivo e também na relação entre a revista e público leitor.

A revista se evidencia, portanto, como um importante veículo de (in)formação para o público jovem e, ao mesmo tempo, de identificação com ele por reproduzir seu comportamento linguístico, ou melhor, reproduzir sua prática discursiva, muitas vezes inusitada, em suas reportagens. Se o jovem se comporta de forma excêntrica, a Superinteressante empenha-se em despertar o interesse desse público ao oferecer-lhe textos bem-humorados, criativos e com engraçadas associações ao cotidiano do leitor, abordando a temática tabu de modo a subvertê-la, ou simplesmente de modo a corroborar, embora não de maneira ortodoxa, sua mitificação em um veículo midiático.

\section{Referências}

ARRUDA, A. Teoria das representações sociais e teorias de gênero. Cadernos de Pesquisa (Fundação Carlos Chagas), Campinas, SP, v. 117, p. 127-147, 2003.

AUGRAS, M. O que é Tabu. São Paulo: Brasiliense, 1989. 
CALSAMIGLIA, H. Divulgar: itinerarios discursivos del saber: una necesidad, un problema, un hecho. Quark, Barcelona: Observatorio de la Comunicación Científica, Universitat Pompeu Fabra, n. 7, p. 9-18, 1997.

CALSAMIGLIA, H.; CASSANY, D. Voces y conceptos en la divulgación científica. Revista Argentina de Lingüistica, Argentina, v. 11-15, p. 173-208, 1999.

CASSANY, D.; MARTÍ, J. Estrategias divulgativas del concepto prión. Quark, Barcelona: Observatorio de la Comunicación Científica, Universitat Pompeu Fabra, n. 12, p. 56-66, 1998.

CATALDI, C. Los Transgénicos en la Prensa Española: una propuesta de análisis discursivo. Barcelona: Universitat Pompeu Fabra, Barcelona, 2003. 409 p. (Tese de Doutorado).

CATALDI, C. A divulgação da ciência na mídia: um enfoque discursivo. In: GOMES, M. C. A.; MELO, M. S. S.; CATALDI, C. Gênero Discursivo, Mídia e Identidade. Viçosa, MG: Ed. UFV, 2007, p. 155-164.

CATALDI, C. A ciência na mídia impressa: a divulgação debate sobre transgênico. In: GOMES, M. C. A.; MELO, M. S. S.; CATALDI, C. Práticas Discursivas: construindo identidades na diversidade. Viçosa, MG: UFV, Programa de Pós-Graduação em Letras PPGLet, 2009, p. 43-63.

CIAPUSCIO, G. Lingüística y divulgación de ciência. Quark, Barcelona: Observatorio de la Comunicación Científica, Universitat Pompeu Fabra, n. 7, p.19-28, 1997.

FREUD. Totem e Tabu. Rio de Janeiro: Imago, 1975.

PRETI, D. A Linguagem Proibida: um estudo sobre a linguagem erótica. São Paulo: T. A. Queiroz, 1984.

REDDY, M. J. A metáfora do conduto: um caso de conflito de enquadramento na nossa linguagem sobre a linguagem. Cadernos de Tradução: Porto Alegre, n. 9, jan/mar, p. 1-72, 2000 .

RODRIGUES, J. C. Tabu do Corpo. Dissertação de mestrado apresentada ao Programa de Pós-graduação em Antropologia Social do Museu Nacional da Universidade Federal do Rio de Janeiro. 3. ed. Rio de Janeiro: Achiamé, 1983.

VILAÇA, M. G. C. Tabus Linguísticos na Publicidade Brasileira. Universidade Federal de Pernambuco, Recife, 2009. 133 p. (Dissertação de Mestrado). 